\title{
Sex differences in glucose levels: a consequence of physiology or methodological convenience? The Inter99 study
}

\author{
K. Færch • K. Borch-Johnsen • A. Vaag • T. Jørgensen • \\ D. R. Witte
}

Received: 23 October 2009 /Accepted: 6 January 2010/Published online: 25 February 2010

(C) Springer-Verlag 2010

\begin{abstract}
Aims/hypothesis We aimed to examine whether sex differences in fasting plasma glucose (FPG), $2 \mathrm{~h}$ post-OGTT plasma glucose $(2 \mathrm{hPG})$ and $\mathrm{HbA}_{1 \mathrm{c}}$ could be explained by differences in body size and/or body composition between men and women in a general non-diabetic Danish population. Moreover, we aimed to study to what degree the newly suggested high-risk $\mathrm{HbA}_{1 \mathrm{c}}$ criteria overlapped with the current OGTT-based criteria of glucose intolerance.

Methods We used cross-sectional data from 6,006 nondiabetic men and women. $\mathrm{HbA}_{1 \mathrm{c}}$ and FPG levels were measured and a $75 \mathrm{~g}$ OGTT was performed in all individuals. Height, weight and waist and hip circumferences were measured and BMI was calculated. Data were analysed in age-adjusted linear regression models.

Results Men had higher FPG and $\mathrm{HbA}_{1 \mathrm{c}}$ levels than women, and women had higher $2 \mathrm{hPG}$ levels than men. Sex differences in $2 \mathrm{hPG}$ levels were explained by differ-
\end{abstract}

K. Færch $(\bowtie) \cdot$ K. Borch-Johnsen · A. Vaag $\cdot$ D. R. Witte

Steno Diabetes Center,

Niels Steensens Vej 2,

DK-2820 Gentofte, Denmark

e-mail: krif@steno.dk

K. Borch-Johnsen

Faculty of Health Sciences, University of Aarhus,

Aarhus, Denmark

T. Jørgensen

Research Centre for Prevention and Health,

Glostrup, Denmark

T. Jørgensen

Faculty of Health Sciences, University of Copenhagen,

Copenhagen, Denmark ences in height and FPG levels, but sex differences in FPG or $\mathrm{HbA}_{1 \mathrm{c}}$ levels were not explained by anthropometric measures. Among individuals with $\mathrm{HbA}_{1 \mathrm{c}}$ in the high-risk range (6.0-6.5\%), 73\% had normal glucose tolerance. Conclusions/interpretation Sex differences in 2hPG levels after an OGTT may to some extent be a consequence of giving the same amount of glucose to individuals with different body size. In contrast, sex differences in FPG and $\mathrm{HbA}_{1 \mathrm{c}}$ levels are likely to have a true physiological basis. In clinical practice, the $\mathrm{HbA}_{1 \mathrm{c}}$ assay may be more convenient than the OGTT, but it is important to note that different populations are identified by the two methods.

Trial registration ClinicalTrials.gov NCT00289237

Funding Supported by grants from the Danish Diabetes Association, the Danish Medical Research Council, the Danish Centre for Evaluation and Health Technology Assessment, Novo Nordisk, GlaxoSmithKline, Copenhagen County, The Danish Heart Foundation, The Danish Pharmaceutical Association, the Augustinus Foundation, the Ib Henriksen Foundation, and the Becket Foundation.

Keywords Anthropometry - Diagnosis · Glucose intolerance $\cdot \mathrm{HbA}_{1 \mathrm{c}} \cdot$ Oral glucose tolerance test $\cdot$ Sex differences
Abbreviations
2hPG $2 \mathrm{~h}$ post-OGTT plasma glucose
FPG Fasting plasma glucose
IFG+IGT Combined impaired fasting glycaemia and
impaired glucose tolerance
i-IFG Isolated impaired fasting glycaemia
i-IGT Isolated impaired glucose tolerance
NGT Normal glucose tolerance 


\section{Introduction}

The prevalence of isolated impaired glucose tolerance (i-IGT) is higher in women than in men, whereas the prevalence of isolated impaired fasting glycaemia (i-IFG) is higher in men than in women [1-4]. While it is unknown why men have a higher prevalence of i-IFG, some studies have recently suggested that the higher prevalence of i-IGT in women may be related to differences in body size between men and women $[1,5,6]$. Men and women are given the same amount of glucose during a standard $75 \mathrm{~g}$ OGTT, and as women are generally shorter and have smaller body size and a smaller absolute amount of fat-free mass than men they may be less able to metabolise the fixed amount of glucose. This notion is supported by the observation of a higher risk of developing type 2 diabetes in men than in women with i-IGT [7], indicating that women with i-IGT may be healthier than their male counterparts. Moreover, women are more commonly diagnosed with diabetes on the basis of $2 \mathrm{~h}$ post-OGTT plasma glucose (2hPG) levels compared with fasting plasma glucose (FPG) levels [8], and the risk of gestational diabetes is higher in shorter compared with taller women [9].

Recently, the International Expert Committee has suggested the use of the $\mathrm{HbA}_{1 \mathrm{c}}$ assay for the diagnosis of diabetes [10]. Furthermore, the committee suggests that the use of the OGTT-based prediabetic groups i-IFG, i-IGT and combined impaired fasting glycaemia and impaired glucose tolerance $(\mathrm{IFG}+\mathrm{IGT})$ should be phased out for the purpose of risk prediction and prevention in clinical practice. Instead, interventions aimed at preventing the development of diabetes should be focused on individuals with $\mathrm{HbA}_{1 \mathrm{c}}$ levels between $6.0 \%$ and $6.5 \%$, as these are at highest risk of developing diabetes [10]. However, the OGTT and other challenge tests will continue to be important in terms of understanding the pathophysiology of individuals at risk of progressing to type 2 diabetes. Moreover, information on the relationship between $\mathrm{HbA}_{1 \mathrm{c}}$ and fasting and post-OGTT glucose levels is necessary if existing evidence from physiological as well as intervention studies in individuals with i-IGT and IFG+IGT are to be applied in high-risk individuals characterised by the newly suggested $\mathrm{HbA}_{1 \mathrm{c}}$ criteria. Therefore, we aimed to examine relationships between sex, anthropometry and glucose levels (FPG, $2 \mathrm{hPG}$ and $\mathrm{HbA}_{1 \mathrm{c}}$ ) in a general non-diabetic Danish population. Specific aims were to examine (1) how FPG, $2 \mathrm{hPG}$ and $\mathrm{HbA}_{1 \mathrm{c}}$ are related to anthropometry and to each other in men and women; (2) whether differences in anthropometry between men and women can explain sex differences in FPG, $2 \mathrm{hPG}$ and $\mathrm{HbA}_{1 \mathrm{c}}$ levels; and (3) to what degree the newly suggested 'high-risk' $\mathrm{HbA}_{1 \mathrm{c}}$ criteria overlap with the OGTT-based criteria of normal glucose tolerance (NGT), i-IFG, i-IGT and IFG+IGT.

\section{Methods}

We used baseline data from the Danish population-based Inter99 study [11], a 5 year non-pharmacological intervention study aimed at reducing the incidence of ischaemic heart disease and type 2 diabetes in 30- to 60-year-old Danes.

\section{Study participants}

A total of 12,934 men and women from the general population were invited to a screening programme at the Research Centre for Prevention and Health in Glostrup in 1999-2001. The initial participation rate was $52.5 \%(n=$ 6,784). All participants gave written informed consent before taking part in the Inter99 study. The protocol was in accordance with the Helsinki declaration, approved by the local ethical committee (KA98155), and registered in ClinicalTrials.gov (NCT00289237). The Inter99 study is described in detail elsewhere [11] (www.Inter99.dk).

\section{Study procedure}

All individuals had a standard $75 \mathrm{~g}$ OGTT after an overnight fast. Plasma glucose concentrations were measured in venous blood samples taken prior to glucose ingestion and after $120 \mathrm{~min}$. Glucose was analysed using the hexokinase/G6P-DH technique (Boehringer, Mannheim, Germany; intra-assay CV $1.1 \%$, inter-assay CV $2.3 \%$ ). Insulin was analysed using the fluoro-immunoassay technique (AutoDEFIA; Perkin Elmer-Wallac, Turku, Finland) and $\mathrm{HbA}_{1 \mathrm{c}}$ was analysed by HPLC Bio-Rad VARIANT (BioRad, CA, USA).

Based on the OGTT, the study participants were classified as having NGT, i-IFG, i-IGT, IFG+IGT or diabetes [12]. Individuals with known or screen-detected diabetes $(n=$ $404)$ or with missing fasting and/or $2 \mathrm{hPG}$ levels $(n=374)$ were excluded from the present study, leaving 6,006 men and women for data analysis. Based on $\mathrm{HbA}_{1 \mathrm{c}}$ levels $(n=$ $5,999)$, the study participants were classified as being at low risk $\left(\mathrm{HbA}_{1 \mathrm{c}}<6.0 \%\right)$, high risk $\left(\mathrm{HbA}_{1 \mathrm{c}} \geq 6.0 \%\right.$ but $<6.5 \%)$ or in the diabetic range $\left(\mathrm{HbA}_{1 \mathrm{c}} \geq 6.5 \%\right)$.

Anthropometry, insulin sensitivity and beta cell function

Height and weight were measured with the participants wearing indoor clothes and no shoes. Waist circumference was measured half way between the lowest point of the costal margin and highest point of the iliac crest, and hip circumference was measured at the level of the greater femoral trochanter; both were measured to the nearest $0.5 \mathrm{~cm}$.

We calculated the homeostasis model assessment of insulin resistance (HOMA-IR) and beta cell function 
(HOMA-beta) using the method of Matthews et al. [13]. An estimate of insulin sensitivity (HOMA-IS) was calculated as 1/HOMA-IR. Since HOMA-IS is based on glucose and insulin levels in the fasting state, it is assumed to reflect hepatic insulin sensitivity more than peripheral insulin sensitivity $[14,15]$. The reason for only using HOMA-IS and HOMA-beta in this study was that these estimates are based on FPG and fasting insulin values. Using data from the OGTT in the calculation of insulin sensitivity and beta cell function would not be appropriate, as it would lead to a circular argument. Our hypothesis was that the OGTTderived data (including glucose and insulin levels) are confounded by the body size of the individual being tested. As this effect would also apply to the indices of insulin sensitivity and beta cell function calculated from the OGTT, we would be introducing some of the sex (and associated body size) differences we wanted to explain.

Statistical analysis

Differences in clinical characteristics between men and women were analysed by one-way ANOVA.

Relationships between anthropometry and FPG, 2hPG and $\mathrm{HbA}_{1 \mathrm{c}}$ and relationships of $2 \mathrm{hPG}$ and $\mathrm{HbA}_{1 \mathrm{c}}$ with $\mathrm{FPG}$ levels were tested in age-adjusted linear regression models stratified by sex. Anthropometric variables were standardised before analysis.

The impact of sex on glucose levels was assessed in ageadjusted linear regression models with FPG, $2 \mathrm{hPG}$ or $\mathrm{HbA}_{1 \mathrm{c}}$ as outcome and sex as explanatory variable. To examine whether anthropometry could explain sex differences in glucose levels, the models were adjusted for height, BMI, waist circumference or hip circumference. Thereafter, we adjusted the models for height together with BMI, height together with waist circumference, or height together with hip circumference. In the models with $2 \mathrm{hPG}$ as outcome we also adjusted for FPG levels, because these could potentially affect the relationship between $2 \mathrm{hPG}$ and sex.

The proportion of individuals categorised in the same category by the OGTT-based vs the $\mathrm{HbA}_{1 \mathrm{c}}$-based definitions was analysed by logistic regression.

Non-normally distributed variables (serum insulin levels, HOMA-IS and HOMA-beta) were $\log _{e}$-transformed before analysis. SAS version 9.1 (SAS Institute, Cary, NC, USA) was used for statistical analysis.

\section{Results}

Characteristics of study participants

Baseline characteristics of men and women stratified by glucose tolerance status are shown in Table 1. Women with
i-IFG had higher $2 \mathrm{hPG}$ levels than men with i-IFG, and women with i-IGT had lower FPG levels than men with i-IGT. $\mathrm{HbA}_{1 \mathrm{c}}$ levels were lower in women than in men with normal FPG levels (i-IGT and NGT), but similar in men and women with elevated $2 \mathrm{hPG}$ levels (i-IFG and IFG+ IGT). Both HOMA-IS and HOMA-beta were slightly but significantly lower in men than in women with NGT, and HOMA-IS was significantly lower in men with i-IGT than in women with i-IGT. The mean $( \pm \mathrm{SD})$ level of commuting and leisure-time physical activity did not differ between men $(291 \pm 162 \mathrm{~min} /$ week $)$ and women $(298 \pm 163 \mathrm{~min} /$ week $)$ ( $p$ for difference $=0.135$ ).

Anthropometry and glucose levels

Standardised $\beta$-coefficients (changes in glucose or $\mathrm{HbA}_{1 \mathrm{c}}$ levels) from associations between anthropometric measures and $2 \mathrm{hPG}, \mathrm{FPG}$ and $\mathrm{HbA}_{1 \mathrm{c}}$ are shown in Table 2.

$2 h P G$ We found positive associations between BMI, waist and hip circumference, and $2 \mathrm{hPG}$ levels among men and women. In contrast, height was inversely associated with 2hPG levels.

FPG Among both men and women, we found positive associations between BMI, waist or hip circumference and FPG levels, but the effects were less pronounced than for $2 \mathrm{hPG}$ levels. Height was not associated with FPG levels in men, and height had only a minor but statistically significant effect on FPG levels in women.

$H b A_{l c}$ In men, height was inversely associated with $\mathrm{HbA}_{1 \mathrm{c}}$ levels, but BMI, waist circumference and hip circumference were not significantly associated with $\mathrm{HbA}_{1 \mathrm{c}}$. In women, height was not associated with $\mathrm{HbA}_{1 \mathrm{c}}$. However, BMI, waist circumference and hip circumference were positively associated with $\mathrm{HbA}_{1 \mathrm{c}}$ levels, although the effects were of limited magnitude (Table 2).

Sex and glucose levels

The results from linear regression models with $2 \mathrm{hPG}$, FPG or $\mathrm{HbA}_{1 \mathrm{c}}$ as outcome and sex as explanatory variable are presented in Table 3.

$2 h P G$ Women had higher $2 \mathrm{hPG}$ levels than men when adjusted only for age. When further adjusted for FPG, this sex difference became larger. However, when adjusted only for age and height, men had higher $2 \mathrm{hPG}$ levels than women. When we additionally adjusted for FPG levels there were no differences in $2 \mathrm{hPG}$ between men and women. $2 \mathrm{hPG}$ levels were still significantly higher among women than among men when height was replaced with 
Table 1 Characteristics of 2,958 men and 3,048 women with NGT, i-IFG, i-IGT and combined IFG+IGT in the Inter99 study

\begin{tabular}{|c|c|c|c|c|c|c|c|c|}
\hline \multirow[t]{2}{*}{ Variable } & \multicolumn{2}{|l|}{ NGT } & \multicolumn{2}{|l|}{ i-IFG } & \multicolumn{2}{|l|}{ i-IGT } & \multicolumn{2}{|l|}{ IFG+IGT } \\
\hline & Men & Women & Men & Women & Men & Women & Men & Women \\
\hline$n$ & 2,209 & 2,526 & 380 & 140 & 224 & 308 & 145 & 74 \\
\hline Age (years) & $45.1(7.8)$ & $45.1(7.9)$ & $48.7(7.1)$ & $49.8(5.8)$ & $48.3(7.8)$ & $46.7(8.2)^{*}$ & $49.7(6.5)$ & $50.6(7.0)$ \\
\hline FPG (mmol/l) & $5.4(0.4)$ & $5.2(0.4)^{* * *}$ & $6.3(0.2)$ & $6.3(0.2)$ & $5.6(0.3)$ & $5.4(0.4)^{* * *}$ & $6.4(0.2)$ & $6.4(0.2)$ \\
\hline $2 \mathrm{hPG}(\mathrm{mmol} / \mathrm{l})$ & $5.4(1.2)$ & $5.6(1.1)^{* * *}$ & $5.8(1.1)$ & $6.2(1.0)^{* *}$ & $8.8(0.8)$ & $8.8(0.9)$ & $9.1(0.9)$ & $9.0(0.8)$ \\
\hline FSI $(\mathrm{pmol} / \mathrm{l})^{\mathrm{a}}$ & $32(22-47)$ & $30(22-43)^{* *}$ & $41(30-61)$ & $44(33-67)$ & $44(27-73)$ & $36(26-62)^{*}$ & $53(40-72)$ & $58(35-79)$ \\
\hline $2 \mathrm{hSI}(\mathrm{pmol} / \mathrm{l})^{\mathrm{a}}$ & $116(67-188)$ & $151(101-222)^{* * *}$ & $146(81-236)$ & $203(129-310)^{* * *}$ & 377 (209-644) & $320(218-533)$ & $393(235-546)$ & $349(250-655)$ \\
\hline HOMA-IS $^{\mathrm{a}}$ & $0.9(0.6-1.3)$ & $1.0(0.7-1.4)^{* * *}$ & $0.6(0.4-0.8)$ & $0.6(0.4-0.8)$ & $0.6(0.4-1.0)$ & $0.8(0.5-1.2)^{* *}$ & $0.5(0.3-0.6)$ & $0.4(0.3-0.7)$ \\
\hline HOMA-beta $^{a}$ & $49(33-71)$ & $52(37-74)^{* * *}$ & $43(31-62)$ & $46(33-65)$ & $62(40-103)$ & $58(39-93)$ & $52(38-73)$ & $58(37-79)$ \\
\hline $\mathrm{HbA}_{1 \mathrm{c}}(\%)$ & $5.8(0.4)$ & $5.7(0.4)^{* * *}$ & $6.0(0.4)$ & $6.0(0.4)$ & $5.9(0.4)$ & $5.8(0.4)^{* * *}$ & $6.1(0.5)$ & $6.0(0.4)$ \\
\hline BMI $\left(\mathrm{kg} / \mathrm{m}^{2}\right)$ & $26.1(3.5)$ & $25.0(4.4)^{* * *}$ & $27.7(4.1)$ & $28.4(5.4)$ & $28.2(4.4)$ & $27.5(5.5)$ & $28.9(4.2)$ & $29.7(6.5)$ \\
\hline Height $(\mathrm{cm})$ & $179.0(6.9)$ & $166.0(6.4)^{* * *}$ & $178.6(6.8)$ & $165.9(5.9)^{* * *}$ & $176.5(6.9)$ & $164.0(6.2)^{* * *}$ & $175.8(6.6)$ & $164.6(5.8)^{* * *}$ \\
\hline $\mathrm{WC}(\mathrm{cm})$ & $91(10)$ & $78(11)^{* * *}$ & $96(11)$ & $88(13)^{* * *}$ & $97(12)$ & $84(13)^{* * *}$ & $98(11)$ & $91(15)^{* * *}$ \\
\hline $\mathrm{HC}(\mathrm{cm})$ & $100(8)$ & $99(10)^{* * *}$ & $103(8)$ & $106(11)^{* * *}$ & $103(8)$ & $103(12)$ & $103(9)$ & $107(14)^{*}$ \\
\hline
\end{tabular}

Data are means $(\mathrm{SD})$ or ${ }^{\mathrm{a}}$ medians (interquartile range)

${ }^{*} p<0.05 ;{ }^{*} p<0.01 ; * * p<0.001$ compared with men in the same glucose tolerance group

2hSI, 2 h serum insulin; FSI, fasting serum insulin; HC, hip circumference; WC, waist circumference

BMI or waist or hip circumference in the models (data not shown). However, when height was included together with hip circumference, $2 \mathrm{hPG}$ levels were highest in men compared with women (Table 3).

FPG and $\mathrm{HbA}_{1 c}$ Men had higher FPG and $\mathrm{HbA}_{1 \mathrm{c}}$ levels than women in the age-adjusted analyses. Adjustment for height or other anthropometric measures did not change the results (Table 3).

Relationships between $2 \mathrm{hPG}, \mathrm{HbA}_{1 \mathrm{c}}$ and FPG levels

Figure 1 shows the relationships of $\mathrm{HbA}_{1 \mathrm{c}}$ and $2 \mathrm{hPG}$ with FPG levels by sex. For FPG levels $<6.5 \mathrm{mmol} / \mathrm{l}$, mean

Table 2 Standardised age-adjusted effects of different anthropometric measures on changes $(95 \% \mathrm{CI})$ in $2 \mathrm{hPG}$, FPG and $\mathrm{HbA}$ lc levels in men and women

\begin{tabular}{llrl}
\hline $\begin{array}{l}\text { Explanatory variable } \\
\text { (per SD unit increase) }\end{array}$ & $\Delta 2 \mathrm{hPG}(\mathrm{mmol} / \mathrm{l})$ & $\Delta \mathrm{FPG}(\mathrm{mmol} / \mathrm{l})$ & $\Delta \mathrm{HbA}_{1 \mathrm{c}}(\%)$ \\
\hline BMI & & & \\
Men & $0.37(0.31,0.42)^{* * *}$ & $0.11(0.09,0.13)^{* * *}$ & $0.01(-0.00,0.03)$ \\
Women & $0.41(0.36,0.46)^{* * *}$ & $0.14(0.12,0.16)^{* * *}$ & $0.05(0.04,0.06)^{* * *}$ \\
Waist circumference & $0.33(0.28,0.39)^{* * *}$ & $0.11(0.09,0.13)^{* * *}$ & $0.01(-0.00,0.03)$ \\
Men & $0.41(0.36,0.46)^{* * *}$ & $0.16(0.14,0.17)^{* * *}$ & $0.06(0.04,0.07)^{* * *}$ \\
Women & $0.19(0.14,0.25)^{* * *}$ & $0.08(0.06,0.09)^{* * *}$ & $0.00(-0.01,0.02)$ \\
Hip circumference & $0.30(0.24,0.35)^{* * *}$ & $0.13(0.11,0.14)^{* * *}$ & $0.04(0.03,0.05)^{* * *}$ \\
Men & $-0.26(-0.32,-0.20)^{* * *}$ & $-0.00(-0.02,0.02)$ & $-0.02(-0.03,-0.00)^{*}$ \\
Women & $-0.22(-0.28,-0.17)^{* * *}$ & $0.02(0.00,0.04)^{*}$ & $-0.01(-0.02,0.01)$ \\
Height & & \\
Men & & & \\
Women & & & \\
\hline
\end{tabular}

${ }^{a}$ BMI: SD men $3.8 \mathrm{~kg} / \mathrm{m}^{2}$; SD women $4.8 \mathrm{~kg} / \mathrm{m}^{2}$. Waist circumference: SD men $11.0 \mathrm{~cm}$; SD women $12.0 \mathrm{~cm}$. Hip circumference: SD men $8.0 \mathrm{~cm}$; SD women $11.0 \mathrm{~cm}$. Height: SD men $7.0 \mathrm{~cm}$; SD women $6.4 \mathrm{~cm}$

$* p<0.05 ; * * * p<0.001$

$\Delta$, change 
Table $3 \beta$-Coefficients (sex differences in glucose or $\mathrm{HbA}_{1 \mathrm{c}}$ levels with corresponding $95 \% \mathrm{CIs}$ ) from linear regression models with $2 \mathrm{hPG}$, FPG or $\mathrm{HbA}_{1 \mathrm{c}}$ as outcomes and sex as explanatory variable
${ }^{a}$ A positive number indicates that the outcome variable is higher in men than in women

HC, hip circumference; WC, waist circumference

\begin{tabular}{llc}
\hline Outcome/adjustment & $\beta$-Coefficient, men vs women ${ }^{\mathrm{a}}(95 \% \mathrm{CI})$ & $p$ value for sex differences \\
\hline 2hPG (mmol/l) & $-0.19(-0.27,-0.12)$ & \\
Age & $-0.47(-0.55,-0.39)$ & $<0.001$ \\
Age, FPG & $0.27(0.16,0.38)$ & $<0.001$ \\
Age, height & $0.01(-0.10,0.11)$ & $<0.001$ \\
Age, height, FPG & $-0.08(-0.19,0.03)$ & 0.893 \\
Age, height, WC & $-0.21(-0.31,-0.10)$ & 0.137 \\
Age, height, WC, FPG & $0.38(0.28,0.49)$ & $<0.001$ \\
Age, height, HC & $0.12(0.01,0.22)$ & $<0.001$ \\
Age, height, HC, FPG & $0.15(0.04,0.25)$ & 0.029 \\
Age, height, BMI & $-0.04(-0.14,0.06)$ & 0.007 \\
Age, height, BMI, FPG & & 0.440 \\
FPG (mmol/l) & $0.30(0.28,0.32)$ & $<0.001$ \\
Age & $0.28(0.25,0.32)$ & $<0.001$ \\
Age, height & $0.17(0.13,0.20)$ & $<0.001$ \\
Age, height, WC & $0.32(0.29,0.35)$ & $<0.001$ \\
Age, height, HC & $0.24(0.21,0.27)$ & $<0.001$ \\
Age, height, BMI & & $<0.001$ \\
HbA 1 (\%) & $0.12(0.10,0.14)$ & $<0.001$ \\
Age & $0.14(0.12,0.17)$ & $<0.001$ \\
Age, height & $0.11(0.08,0.14)$ & $<0.001$ \\
Age, height, WC & $0.15(0.13,0.18)$ & $<001$ \\
Age, height, HC & $0.13(0.10,0.16)$ & \\
Age, height, BMI & & \\
\hline & & \\
\hline
\end{tabular}
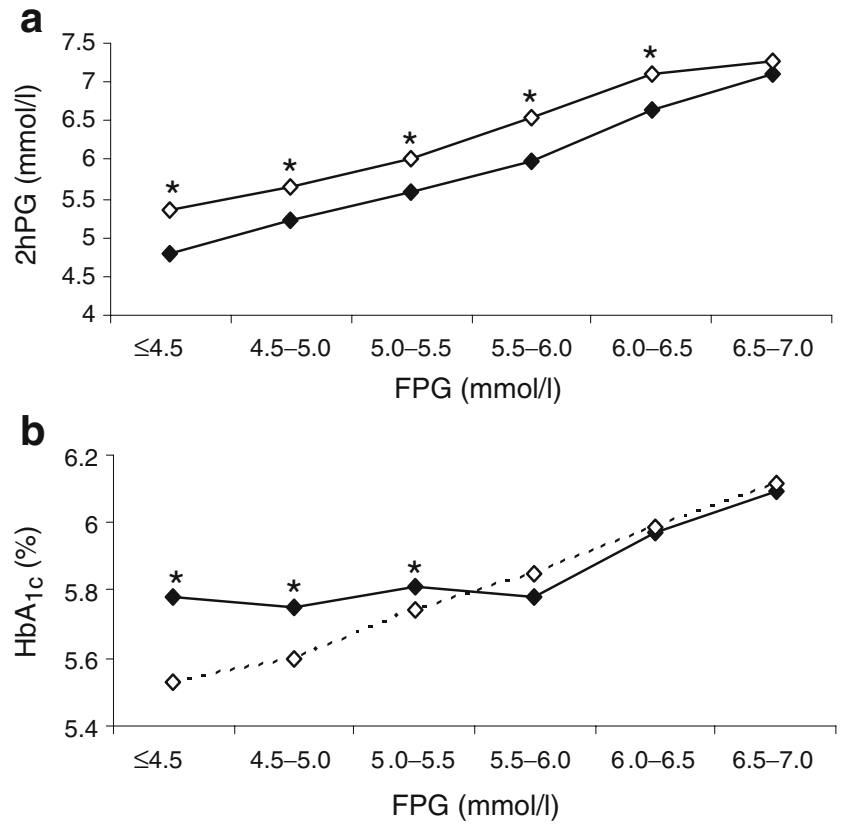

Fig. $12 \mathrm{hPG}$ (a) and $\mathrm{HbA}_{1 \mathrm{c}}$ (b) levels as a function of FPG in men (black diamonds) and women (white diamonds). ${ }^{*} p<0.05$
$2 \mathrm{hPG}$ levels were higher in women than in men. Despite that, mean $\mathrm{HbA}_{1 \mathrm{c}}$ levels were lower in women than in men for FPG levels $<5.5 \mathrm{mmol} / \mathrm{l}$. For FPG levels in the range 5.5-7.0 mmol/1, mean $\mathrm{HbA}_{1 \mathrm{c}}$ levels did not differ between men and women (Fig. 1).

$\mathrm{HbA}_{1 \mathrm{c}^{-}}$vs OGTT-based criteria

The proportions of men and women with NGT, i-IFG, i-IGT and IFG+IGT who had $\mathrm{HbA}_{1 \mathrm{c}}$ levels in the normal $(<6.0 \%$ ), high-risk $(\geq 6.0 \%$ but $<6.5 \%)$ and diabetic range $(\geq 6.5 \%)$ are shown in Fig. 2. Of women with i-IGT, $66 \%$ had $\mathrm{HbA}_{1 \mathrm{c}}$ levels $<6.0 \%$, whereas the corresponding

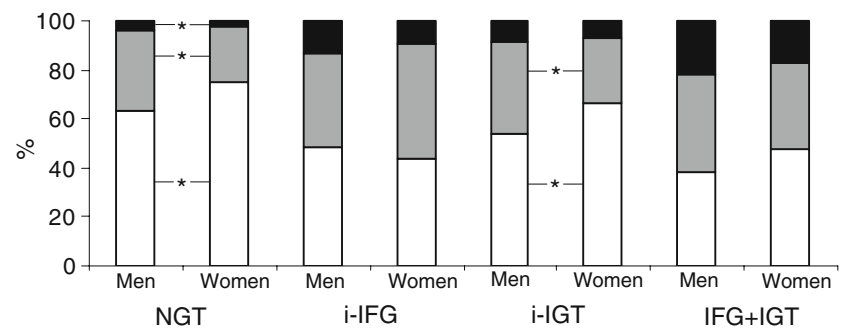

Fig. 2 Proportions of men and women with $\mathrm{HbA}_{1 \mathrm{c}}$ levels $<6.0 \%$ (white), $\geq 6.0 \%$ but $<6.5 \%$ (grey) and $\geq 6.5 \%$ (black) stratified by glucose tolerance status. ${ }^{*} p<0.05$ for difference in proportion between men and women within the same glucose tolerance group 
number for men with i-IGT was 54\% ( $p$ for difference $=$ 0.003 ). In addition, fewer women than men with i-IGT had $\mathrm{HbA}_{1 \mathrm{c}}$ levels in the high-risk range (27\% in women vs $38 \%$ in men, $p=0.010$ ). More than $40 \%$ of those with IFG+IGT had $\mathrm{HbA}_{1 \mathrm{c}}$ levels $<6.0 \%$. Of all individuals with $\mathrm{HbA}_{1 \mathrm{c}}$ in the high-risk range $(6.0-6.5 \%), 5 \%$ had IFG+IGT, $10 \%$ had i-IGT and $12 \%$ had $\mathrm{i}-\mathrm{IFG}$, leaving $73 \%$ with NGT in the high-risk group.

\section{Discussion}

In this large population-based study we showed that the higher FPG and $\mathrm{HbA}_{1 \mathrm{c}}$ levels observed in men compared with women are not related to differences in anthropometry but rather reflect differences in insulin sensitivity and beta cell function between men and women. In contrast, the higher $2 \mathrm{hPG}$ levels observed in women compared with men may be an artefact caused by the fact that individuals of different body size and body composition receive the same amount of glucose during OGTTs. These findings underscore the relevance, but also the difficulties, of combining human physiology with clinically applicable methods.

Regarding $2 \mathrm{hPG}$ levels, we showed that women do not have higher $2 \mathrm{hPG}$ levels than men when differences in height are taken into account. In fact, our study showed that men had higher $2 \mathrm{hPG}$ levels than women for a given height. Therefore, sex differences in $2 \mathrm{hPG}$ and in the prevalence of i-IGT, as documented in previous studies [1-3], are probably not related to sex-specific differences in the physiology of glucose regulation. This finding was further supported by the fact that more women than men with i-IGT had $\mathrm{HbA}_{1 \mathrm{c}}$ levels $<6.0 \%$ and that $2 \mathrm{hPG}$ levels were higher in women than in men, despite lower or similar $\mathrm{HbA}_{1 \mathrm{c}}$ levels (Fig. 1). A previous study showed that the increments of glucose, insulin and the incretin hormones glucagon-like peptide-1 and glucose-dependent insulinotropic polypeptide after an OGTT were significantly higher in women than in men [16], which may support the notion that $75 \mathrm{~g}$ glucose represents a larger stimulus in women than in men when seen in relation to their body size.

Our results support the findings from the AusDiab study [1], indicating that sex differences in $2 \mathrm{hPG}$ levels are explained by differences in height between men and women. The authors of the AusDiab study suggest that the inverse association between height and 2hPG levels reflects the larger amount of metabolically active tissue that tall individuals have available for metabolising the fixed amount of glucose compared with short individuals. This hypothesis was recently supported by the KORA Survey 2000 , showing that sex differences in $2 \mathrm{hPG}$ levels could be explained by differences in the absolute amount of fat-free mass between men and women [5]. Unfortunately, we did not have measures of fat-free mass in our study participants, but we expanded our analysis to include other measures of anthropometry-BMI, waist and hip circumference. We found that high waist circumference, hip circumference and BMI were associated with elevated $2 \mathrm{hPG}$ levels in both men and women. These relationships are likely to be due to obesity-related disturbances of glucose metabolism. Especially the visceral component of abdominal fat is strongly associated with insulin resistance [17], and thereby with a reduced ability to metabolise the glucose load of an OGTT. Interestingly, BMI in itself did not explain sex differences in $2 \mathrm{hPG}$ levels. Whether this indicates that BMI is not as good a proxy measure of fat-free mass as height, or whether other mechanisms than fat-free mass explain the effect of height on $2 \mathrm{hPG}$ levels, can only be speculated.

Several studies have shown that shorter stature is associated with higher $2 \mathrm{hPG}$ levels, [1, 18-20], and genetic or pre- and postnatal environmental factors have been suggested as explanatory mechanisms [21, 22]. If the association between height and 2hPG levels is causally related to inherent metabolic abnormalities, we would expect $\mathrm{HbA}_{1 \mathrm{c}}$ levels to also be affected by height. However, we showed that the effect of height on $\mathrm{HbA}_{1 \mathrm{c}}$ was only of modest magnitude and therefore not potentially clinically relevant. Therefore, the effect of height on $2 \mathrm{hPG}$ levels may not be related to true disturbances of glucose metabolism, but rather related to the fact that short individuals receive relatively more glucose than tall individuals during a standard OGTT.

Sex differences in FPG levels were not explained by differences in anthropometry between men and women. Therefore, physiological mechanisms are likely to be responsible for the higher FPG levels observed in men compared with women. Previously, we have shown in the Inter99 population that a 5 year increase in FPG levels was best predicted by large waist circumference in men and by BMI in women [20], suggesting that some sex differences in body composition may contribute to the higher prevalence of i-IFG in men. The prediabetic condition i-IFG is characterised by hepatic insulin resistance, elevated hepatic glucose production and beta cell dysfunction [23]. We showed that HOMA-IS, predominantly reflecting hepatic insulin sensitivity, in general was lower in men than in women. Interestingly, HOMA-beta was also slightly lower in men with NGT than in women with NGT, indicating that the sex differences in FPG levels are caused by underlying physiological differences in both insulin sensitivity and beta cell function. However, more precise measures of insulin sensitivity and beta cell function are needed to improve our understanding of sex differences in fasting glucose regulation. 
In clinical practice, there is a need for simplicity and convenience in diagnostic testing. These considerations may well have contributed to the choice of the 75 g OGTT as the official standard for the diagnosis of diabetes [24]. However, from a physiological perspective, a challenge test adjusted to the physiognomy of the tested individual would be a more informative test. This would argue for a challenge test adjusted by weight, height or other anthropometric measures. However, such a test would encounter practical difficulties as individuals with different degrees of glucose tolerance respond differently to different amounts of glucose. For instance, the glucose responses to 50 vs $100 \mathrm{~g}$ oral glucose are almost identical in individuals with NGT, while the glucose responses are very different in individuals with impaired beta cell function [25]

Similar to our findings regarding FPG levels, sex differences in $\mathrm{HbA}_{1 \mathrm{c}}$ levels could not be explained by differences in body composition (Table 3 ). This indicates that the $\mathrm{HbA}_{1 \mathrm{c}}$ assay may offer a sex-neutral tool for diagnosing type 2 diabetes and intermediate hyperglycaemia. The newly suggested $\mathrm{HbA}_{1 \mathrm{c}}$ criteria for the diagnosis of diabetes will arguably be more simple and convenient than the OGTT, and will also provide a physiologically relevant measure of in vivo glucose metabolism. However, by applying the suggested $\mathrm{HbA}_{1 \mathrm{c}}$ criteria of $6.0-6.5 \%$ to identify high-risk individuals [10], the overlap with the previous glucose-based definitions (i-IFG, i-IGT and IFG + IGT) is very small with almost three out of four individuals with $\mathrm{HbA}_{1 \mathrm{c}}$ levels in the range $6.0-6.5 \%$ having NGT. Of course, these numbers will vary across populations, but our findings strongly indicate that the OGTT and the $\mathrm{HbA}_{1 \mathrm{c}}$ criteria will define different populations at risk. Since most primary prevention studies have focused on those with i-IGT and IFG+IGT [26-28], it is therefore questionable whether the results from such studies can be applied directly to high-risk individuals diagnosed by $\mathrm{HbA}_{1 \mathrm{c}}$ levels. Such a translation is likely to require a stratified reanalysis of the evidence from prospective prevention trials by the newly suggested $\mathrm{HbA}_{1 \mathrm{c}}$ levels. Alternatively, new follow-up studies of diabetes prevention among individuals in the $\mathrm{HbA}_{1 \mathrm{c}}$-based high-risk range should be performed.

Acknowledgements This study was supported by grants from the Danish Diabetes Association, the Danish Medical Research Council, the Danish Centre for Evaluation and Health Technology Assessment, Novo Nordisk, GlaxoSmithKline, Copenhagen County, the Danish Heart Foundation, the Danish Pharmaceutical Association, the Augustinus Foundation, the Ib Henriksen Foundation and the Becket Foundation. The Inter99 study was initiated by T. Jørgensen (principal investigator [PI]), K. Borch-Johnsen (co-PI), H. Ibsen and T. Thomsen. The Inter99 steering committee comprises T. Jørgensen, $\mathrm{K}$. Borch-Johnsen and C. Pisinger. The authors thank the staff of Inter99 and all the participants.
Duality of interest K. Borch-Johnsen is head of the Steno Diabetes Center, a hospital integrated in the Danish National Healthcare Service, but owned by Novo Nordisk. K. Borch-Johnsen holds shares in Novo Nordisk. The other authors declare that they have no duality of interest associated with this manuscript.

\section{References}

1. Sicree RA, Zimmet PZ, Dunstan DW, Cameron AJ, Welborn TA, Shaw JE (2008) Differences in height explain gender differences in the response to the oral glucose tolerance test: the AusDiab study. Diabet Med 25:296-302

2. Williams JW, Zimmet PZ, Shaw JE et al (2003) Gender differences in the prevalence of impaired fasting glycaemia and impaired glucose tolerance in Mauritius. Does sex matter? Diabet Med 20:915-920

3. Tripathy D, Carlsson M, Almgren P et al (2000) Insulin secretion and insulin sensitivity in relation to glucose tolerance: lessons from the Botnia Study. Diabetes 49:975-980

4. Glümer C, Jørgensen T, Borch-Johnsen K (2003) Prevalences of diabetes and impaired glucose regulation in a Danish population: the Inter99 study. Diabetes Care 26:2335-2340

5. Rathmann W, Strassburger K, Giani G, Döring A, Meisinger C (2008) Differences in height explain gender differences in the response to the oral glucose tolerance test. Diabet Med 25:13741375

6. Janghorbani M, Amini M (2008) Effects of gender and height on the oral glucose tolerance test: the Isfahan diabetes prevention study. Rev Diabet Stud 5:163-170

7. Magliano DJ, Barr ELM, Zimmet PZ et al (2008) Glucose indices, health behaviors, and incidence of diabetes in Australia. Diabetes Care 31:267-272

8. Tuomilehto J, Lindstrom J, Keinanen-Kiukaanniemie S et al (2003) Age- and sex-specific prevalences of diabetes and impaired glucose regulation in 13 European cohorts. Diabetes Care 26:61-69

9. Anastasiou E, Alevizaki M, Grigorakis SJ, Philippou G, Kyprianou M, Souvatzoglou A (1998) Decreased stature in gestational diabetes mellitus. Diabetologia 41:997-1001

10. International Expert Committee (2009) International Expert Committee report on the role of the $\mathrm{A} 1 \mathrm{C}$ assay in the diagnosis of diabetes. Diabetes Care 32:1327-1334

11. Jørgensen T, Borch-Johnsen K, Thomsen TF, Ibsen H, Glümer C, Charlotta P (2003) A randomized non-pharmacological intervention study for prevention of ischaemic heart disease: baseline results Inter99 (1). Eur J Cardiovasc Prev Rehabil 10:377-386

12. Alberti KGMM, Zimmet PZ (1998) Definition, diagnosis and classification of diabetes mellitus and its complications. Part 1: diagnosis and classification of diabetes mellitus. Report of a WHO consultation. Diabet Med 15:539-553

13. Matthews DR, Hosker JP, Rudenski AS, Naylor BA, Treacher DF, Turner RC (1985) Homeostasis model assessment: insulin resistance and beta-cell function from fasting plasma glucose and insulin concentrations in man. Diabetologia 28:412-419

14. Matsuda M, DeFronzo RA (1999) Insulin sensitivity indices obtained from oral glucose tolerance testing: comparison with the euglycemic insulin clamp. Diabetes Care 22:1462-1470

15. Abdul-Ghani MA, Jenkinson CP, Richardson DK, Tripathy D, DeFronzo RA (2006) Insulin secretion and action in subjects with impaired fasting glucose and impaired glucose tolerance: results from the Veterans Administration Genetic Epidemiology study. Diabetes 55:1430-1435

16. Vaag AA, Holst JJ, Vølund A, Beck-Nielsen HB (1996) Gut incretin hormones in identical twins discordant for non-insulindependent diabetes mellitus (NIDDM): evidence for decreased 
glucagon-like peptide 1 secretion during oral glucose ingestion in NIDDM twins. Eur J Endocrinol 135:425-432

17. Wagenknecth LE, Langefeld CD, Scherzinger AL et al (2003) Insulin sensitivity, insulin secretion, and abdominal fat. The Insulin Resistance Atherosclerosis Study (IRAS) family study. Diabetes 52:2490-2496

18. Brown DC, Byrne CD, Clark PMS et al (1991) Height and glucose tolerance in adult subjects. Diabetologia 34:531-533

19. Mooy JM, Grootenhuis PA, de Vries H et al (1995) Prevalence and determinants of glucose intolerance in a Dutch Caucasian population. The Hoorn Study. Diabetes Care 18:1270-1273

20. Færch K, Vaag A, Witte DR, Jørgensen T, Pedersen O, BorchJohnsen K (2009) Predictors of future fasting and 2-hour postOGTT plasma glucose levels in middle-aged men and women: the Inter99 study. Diabet Med 26:377-383

21. Jensen CB, Storgaard H, Dela F, Holst JJ, Madsbad S, Vaag AA (2002) Early differential defects of insulin secretion and action in 19-year-old Caucasian men who had low birth weight. Diabetes 51:1271-1280

22. Leger J, Levy-Marchal C, Bloch J et al (1997) Reduced final height and indications for insulin resistance in 20 year olds born small for gestational age: regional cohort study. BMJ 315:341-347
23. Færch K, Borch-Johnsen K, Holst JJ, Vaag A (2009) Pathophysiology and aetiology of impaired fasting glycaemia and impaired glucose tolerance: does it matter for prevention and treatment of type 2 diabetes? Diabetologia 52:1714-1723

24. World Health Organization (1980) WHO Expert Committee on Diabetes Mellitus. Second report. World Health Organ Tech Rep Ser 646:1-80

25. de Nobel E, van't-Laar A (1978) The size of the loading dose as an important determinant of the results of the oral glucose tolerance test: a study in subjects with slightly impaired glucose tolerance. Diabetes 27:42-48

26. Knowler WC, Barrett-Connor E, Fowler SE et al (2002) Reduction in the incidence of type 2 diabetes with lifestyle intervention or metformin. N Engl J Med 346:393-403

27. Pan XR, Li GW, Hu YH et al (1997) Effects of diet and exercise in preventing NIDDM in people with impaired glucose tolerance. The Da Qing IGT and Diabetes Study. Diabetes Care 20: 537-544

28. Tuomilehto J, Lindström J, Eriksson JG et al (2001) Prevention of type 2 diabetes mellitus by changes in lifestyle among subjects with impaired glucose tolerance. N Engl J Med 344: $1343-1350$ 